\title{
How personality shapes third-party moral judgment
}

Flora Schwartz ${ }^{1}$, Hakim Djeriouat ${ }^{2}, \&$ Bastien Trémolière $^{1}$

${ }^{1}$ UNIV. NIMES, APSY-V, F-30021 Nîmes Cedex 1, France.

${ }_{2}$ UNIV. LYON 269676 Bron Cedex, France.

Corresponding author: flora.schwartz@unimes.fr

This paper has not been peer-reviewed yet 


\begin{abstract}
The present preregistered study investigated the influence of personality traits on third-party moral judgment, with specific predictions about honesty-humility, emotionality, and conscientiousness. Participants $(\mathrm{N}=405)$ completed the HEXACO personality questionnaire and read short narratives describing the interaction between an agent and a victim. We manipulated the intent of the agent (harmful or neutral) and the outcome for the victim (harmful or neutral) and participants judged the agent's behavior. While higher honesty-humility was associated with harsher judgment overall, higher emotionality was associated with harsher judgment of a malevolent agent, and higher conscientiousness was associated with harsher judgment of an agent who harmed intentionally. The results thus suggest that third-party moral judgment is selectively modulated by personality traits depending on the agent's intention.
\end{abstract}

Keywords: third-party morality; personality traits; intent; outcome 


\section{Introduction}

Human societies are grounded on a set of conventional and moral rules that promote large-scale cooperation (Tomasello \& Vaish, 2013). Peaceful interactions are also maintained by legal systems which aim to constrain rule-breaking conducts and prevent their occurrence as much as possible. Oftentimes, the responsibility of judging the agent of a moral transgression is deferred to independent third-party judges to minimize partiality. The examples are multiple and involve low as well as high stake situations. For example, in many countries, members of a popular jury in court will determine whether and how much to punish a defendant. As impartial as they try to be, third-party judges do not always achieve unanimity. Jury court dissensus can be explained in terms of complexity of the case, differential interpretation of the facts, how information is abstracted from case-file and evidence analyses (Kaplan \& Miller, 1978; Pennington \& Hastie, 1986), or else potential media coverage and social origins of the defendant (Brady, 1983). A range of situational and individual factors are thus likely to influence the mental representation of the events and the defendants, thereby contributing to judgment severity. Understanding how individuals make moral judgments lies at the intersection between Law, Philosophy and Psychology and investigations over the past years have started to uncover the psychological mechanisms involved in third-party moral judgment.

\subsection{A two-process model of third-party moral judgment}

At the time of assessing a moral transgression, people mainly process two components to reach their judgment: Intention (whether or not the agent had the intent to hurt someone) and the outcome (whether or not the victim was hurt as a result of the action taken). Critically, analyses of the intention to harm and the outcome for the victim are thought to be processed by distinct cognitive systems. According to the dual-process model of moral judgment (Cushman, 2008; Greene et al., 2009), which is the most widely accepted theoretical framework to date, moral judgment is based on two complementary mental processes: the outcome-based and intent-based processes. The fast and automatic outcome-based process focuses on the consequences of a moral transgression for the victim. Conversely, the intent-based process 
focuses on the examination of the agent's intentions (i.e., utilitarian motive for the killing, malevolent intention) and is slower and more costly.

Of critical importance is that the output of the two processes are sometimes opposed, triggering a cognitive conflict in the psychological processes at work (Greene et al., 2004). A typical case in which a conflict is present is during the judgment of accidental moral transgressions, when the agent unintentionally harms someone else, resulting in more or less severe consequences. In this case, the fast outcome-based process focuses on the harm inflicted to the victim and would increase the severity of the judgment, while the intent-based process focuses on the agent's innocent intentions and would decrease judgment severity. The presence of a cognitive conflict seems specific to accidental harm; this conflict is not triggered in the case of attempted harm, for which there is no salient negative outcome. Interestingly, individual differences are observed in the weight people attribute to the perpetrator's intent or the transgression's outcome and this might be associated with individual differences in solving this conflict. Actually, it may depend on a range of factors, such as susceptibility to implicit bias (Kang et al., 2012), political ideology (Clark \& Wink, 2012) or thinking dispositions (Gunnell \& Ceci, 2010; Patil et al., 2021). For example, individual political ideology predicts some differences in punishment severity, with conservatives allowing harsher fines (Clark \& Wink, 2012). As another example, people with a more intuitive thinking style are for instance more likely to render a guilty verdict when analyzing case files for which the defendants appear less attractive in photographs than people more analytic (Gunnell \& Ceci, 2010). Thinking style is also associated with individual differences in intent-based analysis following an accidental moral transgression (Patil et al., 2021).

Interestingly, individual differences in personality are also good candidates as moderators of the way people resolve such a cognitive conflict when judging the agent of accidental harm. To our knowledge, although the literature has shown some relationships between personality and moral judgment in the framework of moral utilitarianism, research has almost overlooked the effect of personality on third-party moral judgment. 


\subsection{Personality and third-party moral judgments}

Although previous studies have tried to bridge the gap between personality traits and verdict preferences (Devine et al., 2001; Shaffer et al., 1986; Shaffer \& Case, 1982), these investigations are limited to legal decisions in court, and less is known about how personality traits predict the relative importance given to the specific components underlying the judgment of everyday moral transgressions, namely intention, and the severity of the outcome. Among the handful of studies on the issue, previous work has for instance suggested that people with dark personalities are less concerned with the victim's harm when they make third-party moral judgments (Djeriouat \& Trémolière, 2014; Trémolière \& Djeriouat, 2016), and people with a more deliberative thinking style are more likely to make judgments decisions whose consequences favor the greater good, that is, benefitting the many by intentionally harming the few (Behnke et al., 2020). However, the joint contribution of the personality variables to different types of moral transgressions is unknown.

In the present research we targeted three specific personality traits, namely, honesty-humility, emotionality and conscientiousness which appear good candidates for the modulation of third-party moral judgment. We expect that these traits may weigh in the balance between the outcome-based and intentbased processes and thus generate variability in judgment severity.

\subsection{Emotionality and the outcome-based process}

Emotionality is a personality trait directly associated with aversion to harm (Cushman \& Young, 2009; Greene et al., 2009). People high in emotionality experience more anxiety in response to dangers and life's challenges, need emotional support from others and have more empathy. People with low emotionality "are not deterred by the prospect of physical harm, feel little worry even in stressful situations, have little need to share their concerns with others, and feel emotionally detached from others" (Ashton \& Lee, 2009). 
Because emotionality is directly associated with aversion to inflicting harm, this personality trait may specifically impact the outcome-based process of moral judgment. This is mainly suggested by research highlighting the role of emotions in the judgment of moral dilemmas (Feinberg et al., 2012; Greene et al., 2001; Moll et al., 2003; Moll \& de Oliveira-Souza, 2007), in which the victim's harm is likely to trigger an emotional reaction (Cushman \& Young, 2009; Greene et al., 2001). Consistent with these findings, emotion reappraisal has been associated with more utilitarianism in moral dilemmas (Feinberg et al., 2012). However, there has been limited research about how individual differences in emotionality shape responses to moral dilemmas. Evidence from subclinical populations suggests that emotional callousness is associated with less aversion to the perspective of the sacrificial option. For instance, higher utilitarianism has been reported in individuals with alexithymia (Patil \& Silani, 2014a), a subclinical condition defined by low emotional interoception and low empathy (Lane et al., 2015) and often found in psychopaths and individuals with autism spectrum disorder (Bird \& Cook, 2013). Consistent with this observation, subclinical psychopathy seems to be related to higher acceptability of harm in moral dilemmas (Behnke et al., 2020; Karandikar et al., 2019).

Beyond moral dilemmas, a more complex interaction between emotionality and different types of harm is suggested by recent investigations in the general population as well as in subclinical samples and neurological patients. For example, in the general population, compassion for the victim is associated with harsher punishment toward the agent of intentional, but not accidental transgressions (Pfattheicher et al., 2019). Furthermore, people reporting higher anger after observing unfair harm inflicted to a victim (in the case of intentional transgressions with no utilitarian motives) make harsher punishment decisions toward the agent in order to compensate the victim (van Doorn et al., 2018). These findings are consistent with other studies including a subclinical population on the lower end of the emotionality spectrum. Subclinical psychopathy is associated with less severe punishment of an agent who harmed intentionally (Hart et al., 2020; Trémolière \& Djeriouat, 2016) or attempted to harm (Djeriouat \& Trémolière, 2014). Additionally, alexithymia was associated with higher acceptability of accidental harm in individuals with autism (Patil \& Silani, 2014b). Finally, patients with ventro-medial prefrontal cortex (vmPFC) lesions, a 
brain region involved in emotion regulation, judged harmful intents less severely (Liane Young et al., 2010).

To sum up, these studies suggest that low emotionality is associated with less concern for the victim's harm overall and less consideration of the agent's motives, while high emotionality is associated with higher concern for the victim and harsher punishment of the agent who harmed intentionally. Building upon research suggesting that moral judgment may be the final output of two competing processes (Cushman, 2008), one intuitive and another deliberative, we now turn to a personality trait which has been associated in the literature with deliberative thinking, that is, conscientiousness.

\subsection{Conscientiousness and the intent-based process}

People high in conscientiousness tend to be organized, disciplined, favor accuracy in their tasks, and carefully deliberate before making decisions (Ashton \& Lee, 2009). Conversely, people low in conscientiousness tend to avoid difficult tasks and make decisions with little reflection. In the context of moral judgment, high conscientiousness trait may be associated with careful examination of the victim's harm on the one hand, and of the agent's intention on the other hand, whereas low conscientiousness may be associated with fast and intuitive decisions based on the victim's harm. This idea is suggested by behavioral and neuroimaging studies using moral dilemmas.

It has indeed been found that experimental manipulations that prevent deliberative thinking, such as time pressure (Suter \& Hertwig, 2011) or cognitive load (Green et al., 2008) affect utilitarian decisions in moral dilemmas. Conversely, facilitating deliberative thinking may favor utilitarianism (Nichols \& Mallon, 2006), and a more deliberative thinking style is accompanied by greater cost-benefit analysis when evaluating moral dilemmas (Bartels, 2008). Additionally, evidence from functional neuroimaging points to a greater involvement of cortical brain regions involved in working memory and cognitive control in participants who make more utilitarian responses to moral dilemmas (Greene et al., 2004). Taken together, these findings suggest the involvement of cognitive resources while making a moral judgment. 
Because conscientiousness seems to play a role in mental shifting (Fleming et al., 2016) and is related to impulse control skills (Roberts et al., 2014), people scoring high on this trait may engage in a more thoughtful examination of intent before making a moral judgment. In line, conscientiousness also reflects the ability to rigorously stick to the rules such as moral and social norms (Roberts et al., 2014). Examination of one's own moral behavior, or moral attentiveness (Reynolds, 2008) also applies to other's behavior (Babalola et al., 2019). It follows that among highly conscientious individuals, moral circumspection would drive a preferential focus on intent-based analysis to evaluate moral norm violation and dismiss emotional distress generated by the harmful consequence.

Additionally, studies on clinical and developmental populations also suggest that executive functioning has a great share in the ability to primarily examine intentional states of an agent and to disentangle mental state analysis from harm-related affect to produce moral judgements. For example, the development of executive functions in children accompanies the shift from outcome-based to intent-based

moral judgment (Zelazo et al., 1996). Additionally, among individuals on the autism spectrum, who show mental shifting deficits and tend to be low in conscientiousness (Schriber et al., 2014), high-functioning autism was associated with the exoneration of agents who only attempted to harm, and with greater severity toward agents who accidentally harmed someone (Moran et al., 2011).

In light of the above evidence and the two-process model of moral judgment, high conscientiousness people may thus be able to shift more easily from the outcome-based to the intentbased process and to examine the agent's mental state, especially when the intent and outcome go in opposite directions, as for accidental harm. But how conscientiousness influences punishment decisions and acceptability of different types of moral transgressions is still unknown.

\subsection{Honesty/Humility and the interaction between intent and outcome}

Because honesty-humility encompasses several facets of moral behavior, it is likely to play a role in third-party moral judgment. This trait subsumes various facets such as honesty, modesty, fairness, and 
greed-avoidance (Ashton \& Lee, 2009). Honesty-humility predicts the active aspect of prosocial behavior (such as help and cooperation; (Hilbig et al., 2013)). It represents fairness, sincerity and honesty versus pretentiousness, conceitedness and narcissism (Lee \& Ashton, 2008). People who score low on honestyhumility feel entitled and motivated to attain profit by exploiting others (Exline \& Geyer, 2004; Perugini et al., 2003).

There is evidence that people high on this trait may be harsher toward an agent who broke -or attempted to break- moral rules. Indeed, prosocial behavior may be accompanied with an increased need for justice and demand of higher compensation for victims of moral transgressions (Fehr \& Gächter, 2002). Conversely, people with antagonistic personality traits, such as narcissism and Machiavellianism (who score low on honesty-humility), show atypical moral judgment for different types of transgressions. For example, people scoring high on the dark triad (Paulhus \& Williams, 2002), or dark tetrad of personality (Furnham et al., 2013) are less severe toward an agent who harmed intentionally (Hart et al., 2020; Trémolière \& Djeriouat, 2016) or who attempted to harm someone (Djeriouat \& Trémolière, 2014). Besides, people under the subclinical range of sadism were harsher toward the agent of accidental harm (Trémolière \& Djeriouat, 2016). In keeping with the idea that honesty-humility may play a role in aversion to harm (Djeriouat \& Trémolière, 2014), this personality trait may predict harsher judgment when the intent to harm is present.

\subsection{The present study}

In the present pre-registered study, we aimed to determine the contribution of personality traits to thirdparty moral judgment, with a specific focus on honesty-humility, emotionality, and conscientiousness. We expected emotionality to modulate the processing of the outcome, while we expected conscientiousness and honesty-humility to modulate the processing of the agent's intent. We predicted that these personality traits will be most important in explaining inter-individual differences when the intent to harm and the outcome are opposed, especially for accidental harm. Specifically, we expected "emotionality" to positively correlate with severity of punishment and blame of the agent following 
accidental moral transgressions, and to negatively correlate with "acceptability" of the agent's behavior. Conversely, we expected "conscientiousness" to negatively correlate with severity of punishment and blame following accidental moral transgressions, and to positively correlate with "acceptability" of the agent's behavior. Finally, we expected "honesty-humility" to positively correlate with severity of punishment and blame following intentional and attempted moral transgressions, and to negatively correlate with "acceptability" of the agent's behavior.

\section{Method}

\subsection{Research Strategy}

Our research plan including the protocol and the hypotheses was pre-registered on the Open Science Framework platform prior to collecting the data. The data, scripts and pre-registration report will be made publicly available pending publication (they are currently under embargo).

\subsection{Sample size rationale}

We used the $\mathrm{G}^{*}$ power software to estimate the minimum sample size for this study. We ran an a-priori power analysis for GLM (fixed model, $\mathrm{R}^{2}$, deviation from 0) with 5 predictors, with alpha $=0.05$, Power $=0.95$, effect size $\mathrm{f}^{2}$ set to 0.05 (small effect size expected). The required sample size to observe such effect size under these assumptions was 402 participants.

\subsection{Participants}

Four hundred and five participants aged 18 or older living in the United Kingdom were invited to complete an online survey on the Prolific service and were paid $£ 7 /$ hour upon completion. Participants who failed attention checks and/ or who were flagged as fraudulent respondents were excluded from 
analysis. Based on these criteria, we excluded 8 participants. The final sample included 397 participants (mean age $=33.9+-13.4$ years, 248 females).

\subsection{Material}

Moral judgment task. An 8 short stories featuring moral transgressions borrowed from Young and colleagues (Young et al., 2010) was used. The stories framed an interaction between an agent and a victim in a daily-life context. The type of moral transgression was manipulated using a 2 x 2 within-subject design with intent (present/absent) and outcome (harm/no harm) as categorical factors. This led to 4 conditions: intentional harm (intent present, harmful outcome), attempted harm (intent present, no harm), accidental harm (no intent, harmful outcome) and neutral as a control condition (no intent, no harm). See Table 1 for an example of a framing that could lead to 4 possible items. (Full description of the scenarios and conditions of moral transgressions is displayed in Appendix A). For each scenario, participants were asked to judge the agent's behavior on three outcome measures, using a 7-point Visual analog scale: (1) how acceptable the agent's behavior is (from "not at all acceptable" to "very acceptable"), (2) how much blame the agent deserves (from "not at all" to "very much"), and (3) how much punishment the agent deserves (from "not at all" to "very much"). 


\begin{tabular}{|c|c|c|}
\hline Background & \multicolumn{2}{|c|}{$\begin{array}{l}\text { Erica is driving home when she sees a runner by the side of the road. The runner is bent } \\
\text { over and has one hand on his chest. There is an empty asthma inhaler on the ground. }\end{array}$} \\
\hline Foreshadow & $\begin{array}{l}\text { Negative } \\
\text { The runner is having a serious asthma attack } \\
\text { and needs to get to a hospital immediately } \\
\text { before he goes into shock. }\end{array}$ & $\begin{array}{l}\text { Neutral } \\
\text { The runner is just short of breath and } \\
\text { has stopped to rest for a moment before } \\
\text { continuing his long jog. }\end{array}$ \\
\hline Intent & $\begin{array}{l}\text { Negative } \\
\text { Because Erica sees the inhaler and the } \\
\text { gasping runner, she believes that the runner is } \\
\text { having an asthma attack and must get to a } \\
\text { hospital immediately. }\end{array}$ & $\begin{array}{l}\text { Neutral } \\
\text { Because Erica doesn't see the inhaler, } \\
\text { she believes that the runner has just } \\
\text { stopped to catch his breath and will } \\
\text { continue his jog shortly. }\end{array}$ \\
\hline Outcome & $\begin{array}{l}\text { Negative } \\
\text { Erica continues to drive, leaving the runner. } \\
\text { The runner faints and collapses. }\end{array}$ & $\begin{array}{l}\text { Neutral } \\
\text { Erica continues to drive, leaving the } \\
\text { runner. The runner catches his breath } \\
\text { and is fine. }\end{array}$ \\
\hline
\end{tabular}

Table 1. Item versions in the moral judgment task. Notes: The same framing leads to 4 intent by outcome combinations. A negative (respectively, neutral) foreshadow always precedes a negative (respectively, neutral) outcome.

Personality traits. Personality traits were assessed using two self-report questionnaires: the HEXACO personality inventory and the sensation seeking scale 5. The HEXACO-60 inventory (Ashton \& Lee, 2009) is a 60-item questionnaire that assesses 6 major personality traits (each consisting of 10 items): Honesty/Humility (e.g., "I would not use flattery to get a rise or a promotion at work, even if I thought it would succeed"), Emotionality (e.g., "I would feel afraid if I had to travel in bad weather conditions"), Extraversion (e.g., "I rarely express my opinion in group meetings"), Agreeableness (e.g., "People sometimes tell me that I am too critical of others"), Conscientiousness (e.g., "I plan ahead and organize things, to avoid scrambling at the last minute"), and Openness to experience (e.g "I would enjoy creating 
a work of art, such as a novel, a song or a painting"). Participants rated their agreement with each item using a 5-point Likert scale, ranging from "Strongly disagree" to "Strongly agree". Means scores are determined for each of the 6 dimensions. All personality dimensions showed a high internal consistency in the current sample (all Cronbach's alpha $>0.77$ ).

The Sensation Seeking Scale 5 (Zuckerman, 2007) is a 40-item questionnaire that assesses the degree to which people are attracted to or engage in high-risk, unconventional, or sensation-seeking activities. The questionnaire consists of 4 dimensions (Thrill, Boredom, Disinhibition, Experience Seeking) each measured with 10 items. For each item, participants are asked to choose between 2 response options the one that best corresponds to them (e.g., "I often wish I could be a mountain climber" vs. "I can't understand people who risk their necks climbing mountains"). Scores were averaged across the 4 dimensions, leading to a mean "sensation seeking" index with a good internal reliability (Cronbach's $\alpha=0.67)$.

\subsection{Procedure}

Participants were told they would be asked questions about the behavior of one of the story's characters. They were presented with the moral judgment task immediately before or after completing the self-report questionnaires (task order was counterbalanced across participants). Participants were presented with 8 moral transgression items ( 2 items / condition). The presentation of items was pseudo-randomized. First, the association between framing and type of moral transgression was counterbalanced across participants. Second, the order of items was fully randomized. After completion of the moral judgment task, participants responded to attention checks.

\subsection{Data analysis}

Responses to the moral judgment task (level of acceptability, blame, and punishment) were analyzed using a within-subject design with "intent" and "outcome" as within-subject factors. We used continuous 
predictors (scores at the HEXACO and Sensation Seeking Scale) to determine how individual differences in moral judgment is explained by personality traits for the different intent by outcome combinations. One item from the moral judgment task ("seatbelt") was excluded from the analysis because the control condition did not show the expected response pattern (low acceptability overall for the neutral condition, while acceptability of the neutral condition was homogeneously high for all other items).

We implemented linear mixed models following the steps outlined by Zuur (Zuur et al., 2009). We first assessed the relevance of using mixed models by computing a general linear model with the factors described above. As the residual variance was large enough, we constructed a series of mixed models. We determined the optimal random effects structure and then the optimal fixed structure. Since models with random slopes failed to converge, we used only random intercepts. Moreover, based on the AIC criteria, the different types of moral transgressions were coded as one 4-level factor (instead of being defined as the "intent" and "outcome" factors). The final model included type of transgression, honestyhumility, emotionality and conscientiousness as fixed factors, with by-subject and by-item random intercepts. The neutral condition (=control) was coded as the reference level of the type of transgression factor. Interaction terms between type of transgression and each of the three personality traits were included in the final model. The final model reads:

moral evaluation $\sim$ transgression + honesty + emotionality + conscientiousness + transgression $*$ honesty + transgression $*$ emotionality + transgression $*$ conscientiousness $+(1$ litem $)+(1 \mid$ subject $)$

Statistical significance of fixed effects and their interaction was obtained using the Satterthwaite approximation implemented in the lmerTest R package (Kuznetsova et al., 2017). The Satterthwaite approximation is one of the methods recommended for studies including a limited number of items (Luke, 2017), as in our case. Post-hoc pairwise comparisons were performed using Tukey tests from the lsmeans package (Lenth, 2016). We also ran exploratory analyses to examine moral evaluation as a function of all 6 personality traits from the HEXACO as well as sensation seeking questionnaires. 


\section{Results}

\subsection{Manipulation check}

Participants' moral judgment for the different types of transgressions was in accordance with the literature on moral psychology. Across evaluations of acceptability, punishment and blame, intentional transgressions were as expected the most severely judged, followed by attempted, and then accidental transgressions, while the most lenient judgment was consistently made for the neutral condition (See Supplementary results and Supplementary Figure 1 for detailed information).

\subsection{Individual personality traits and moral judgment}

To better visualize the contribution of specific personality traits independently of one another, we first ran Pearson's correlations between moral judgment (acceptability, punishment and blame) associated with each type of transgression (accidental, attempted, intentional, neutral), and all personality measures. Results are presented in Appendix B.

Next, in keeping with our preregistration, we determined the contribution of 3 of these personality traits to moral judgment in our main analyses (honesty-humility, emotionality, conscientiousness). We first implemented linear mixed models for each type of moral evaluation (acceptability, punishment and blame), with type of transgression as categorical factor, personality traits (honesty-humility, emotionality, and conscientiousness) as continuous predictors and by-item and by-subject random intercepts. We report the main effects and interaction terms of the full model. Secondly, we implemented linear mixed models for each type of transgression separately, with personality traits as fixed factors and by-item and bysubject random intercepts. This step allowed us to assess more specifically the relative contribution of personality traits to each type of moral transgressions.

First, we found a main effect of honesty-humility on acceptability of the agent's behavior $(F=$ $\left.15.67, p=8.92 \cdot 10^{-5}\right)$. Honesty-humility decreased acceptability of accidental $(b=-0.030, S E=0.012, p=$ 0.017), and neutral transgressions $(b=-0.022, S E=0.0091, p=0.016)$, and tended to do so for attempted 
transgressions $(b=-0.017, S E=0.010, p=0.099)$, but did not significantly affect acceptability of intentional transgressions $\left(b=-2.10^{-5}, S E=0.0068, p=0.99\right)$ (Figure 1, left panel). However, the main effect of honesty-humility was not significant on blame $(F=2.02, p=0.15)$ and punishment $(F=1.21, p$ $=0.27$ ), and this trait did not contribute to punishment and blame judgments for any transgression (Figure 1 , central and right panels).

Second, emotionality contributed to acceptability ratings overall $(F=3.83, p=0.051)$. More specifically, emotionality reduced acceptability of attempted transgressions $(b=-0.029, S E=0.010, p=$ 0.0043) (Figure 2, left panel). Moreover, although the main effect of emotionality did not reach significance for decisions of blame $(F=2.09, p=0.15)$ and punishment $(F=1.28, p=0.26)$, the interaction with the type of transgression was significant for blame $(F=3.10, p=0.026)$ and marginally significant for punishment $(F=2.18, p=0.088)$. In the case of intentional transgressions, emotionality marginally increased blame $(b=0.017, S E=0.009, p=0.074)$ and punishment $(b=0.019, S E=0.01, p=$ 0.053) (Figure 1, central and right panels).

Third, conscientiousness did not significantly modulate overall ratings of acceptability $(F=0.35$, $p=0.56)$, punishment $(F=0.060, p=0.81)$ and blame $(F=0.039, p=0.84)$. However, conscientiousness decreased acceptability of the agent's behavior following intentional transgressions specifically $(b=$ 0.017, SE $=0.0077, p=0.027)$ (Figure 1, left panel). 

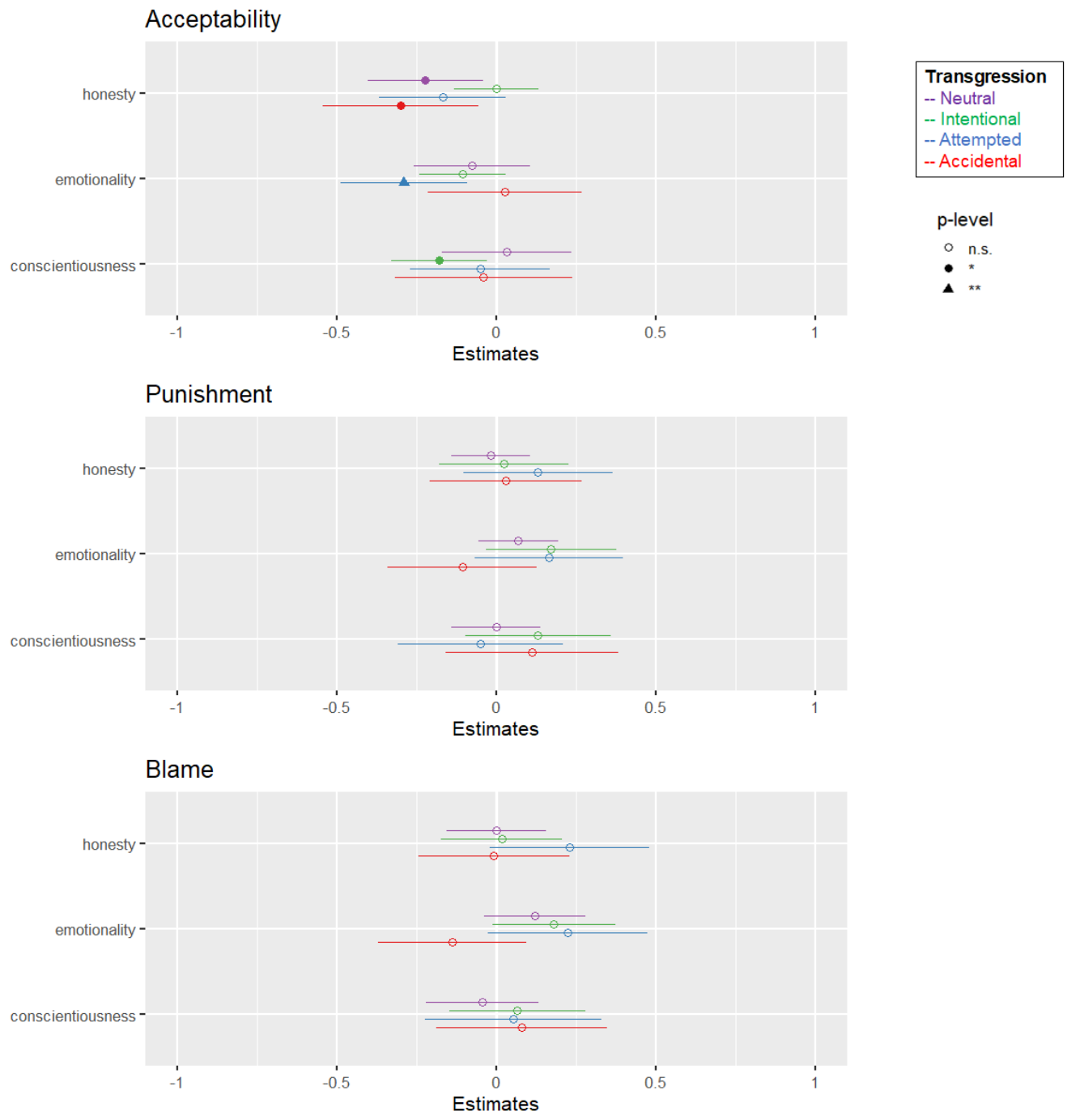

Figure 2. Contribution of Honesty-Humility, Emotionality and Conscientiousness to moral judgments

\section{Exploratory analyses}

In the pre-registered exploratory analyses, we added the remaining personality variables from the HEXACO (openness to experience, agreeableness, extraversion) as well as sensation seeking questionnaires in the mixed models in order to account for a larger range of personality traits. Importantly, in addition to preserving the specific contributions of honesty-humility, emotionality and conscientiousness to judgments of acceptability (as reported previously), inclusion of the remaining 
personality traits revealed (1) the significant or marginally significant contribution of extraversion on judgments of blame $(F=7.28, p=0.0073)$ and punishment $(F=3.22, p=0.073),(2)$ the interaction between openness to experience and type of transgression for acceptability ratings $(F=3.66, p=0.012)$, explained by a negative correlation between openness to experience and acceptability of the agent's behavior following attempted transgressions $(b=-0.024, S E=0.010, p=0.014),(3)$ a marginally significant effect of sensation seeking on overall punishment decisions $(F=2.99, p=0.084)$, and (4) enhanced the contribution of emotionality to overall acceptability $(F=5.52, p=0.019)$ as well as to decisions of blame $(b=0.021, S E=0.011, p=0.065)$ and punishment $(b=0.021, S E=0.012, p=0.086)$ following intentional transgressions specifically (Figure 2). In unplanned exploratory analyses, we determined whether the influence of personality traits on moral judgment was dependent on gender. As gender differences have been reported in honesty-humility and emotionality (Weller et al., 2018), we controlled for this potential confound (supplementary results). The main effect of gender was not significant, but gender interacted with conscientiousness for judgments of acceptability $(F=4.34, p=$ $0.038)$. 

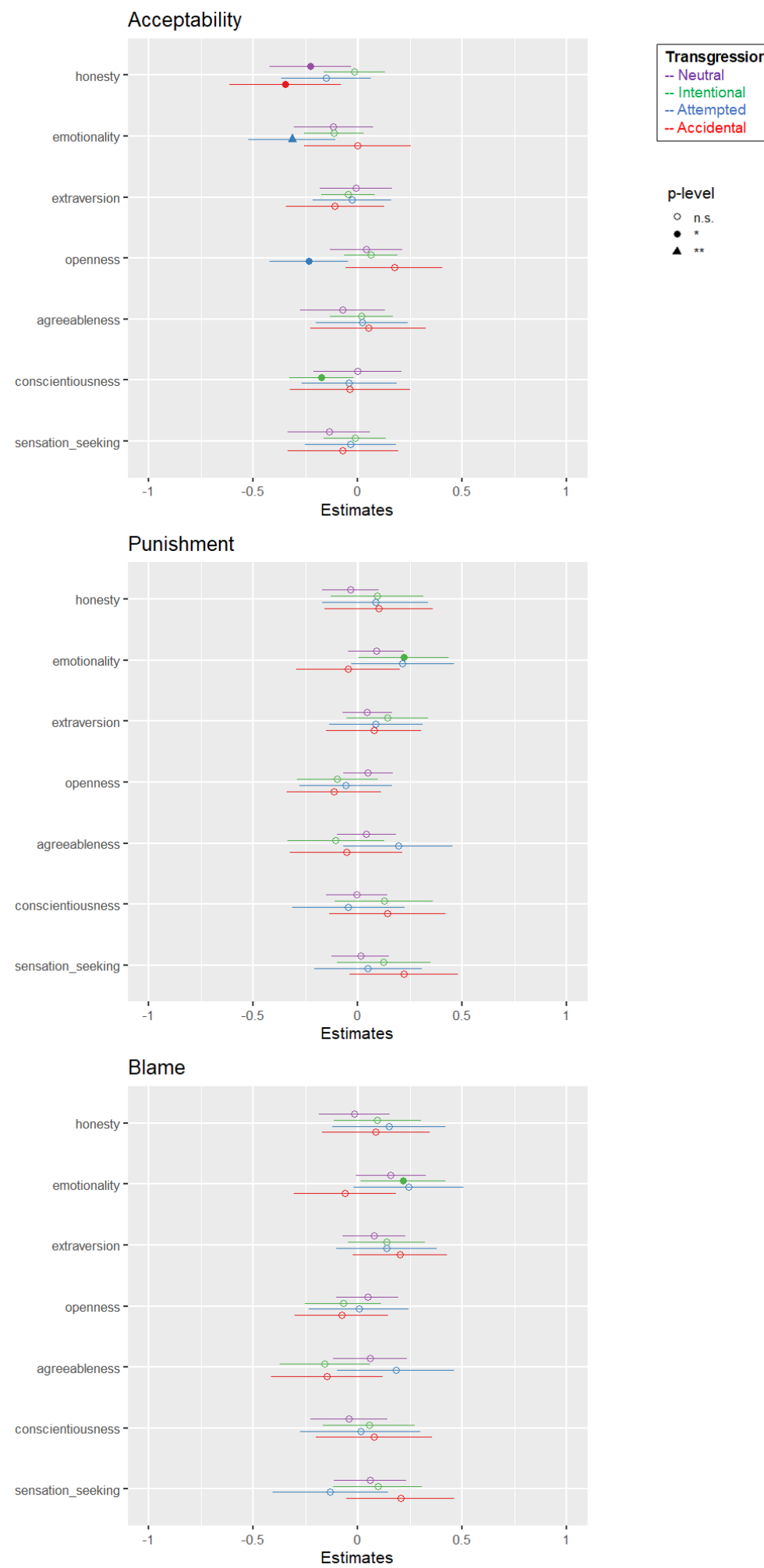

Figure 3. Contribution of the HEXACO personality and sensation seeking measures to moral judgments. 


\section{Discussion}

We investigated the contribution of personality traits to third-party moral judgment. Across different intent by harm combinations, we found that judgment severity for the different types of transgressions was selectively modulated by personality variables. While higher honesty-humility scores were associated with lower acceptability of moral transgressions overall, emotionality and openness to experience were negatively correlated with acceptability ratings when the agent attempted to harm, and conscientiousness was negatively correlated with acceptability of intentional harm. We also found that emotionality moderately increased punishment and blame of an agent who harmed intentionally.

\subsection{Emotionality modulates the intent-based process of moral judgment}

Our finding that emotionality contributes to moral judgment is in line with the literature that used moral dilemmas in typical populations (Conway et al., 2018; Crockett et al., 2010; Greene et al., 2004; Suter \& Hertwig, 2011) as well as with evidence of atypical moral judgment in subclinical or clinical populations with emotional deficits (Djeriouat \& Trémolière, 2014; Karandikar et al., 2019; Patil \& Silani, 2014b; Young et al., 2010). Alexithymia has for instance been associated with less concern for the victim (Patil \& Silani, 2014a) and psychopathy has been associated with less concern over a victim's death (Behnke et al., 2020).

However, contrary to our hypothesis, we found that emotionality predicts acceptability of attempted harm, but not accidental harm. Moreover, after adding extraversion to the model in exploratory analyses, emotionality also tended to predict punishment decisions and blame of intentional harm. These results suggest that emotionality may sometimes modulate the intent-based process as much as (or even more so than) the outcome-based process when deciding about moral wrongness. This is consistent with some recent revisions of the dual-process model of moral judgment (Cushman, 2013), which posit that 
affect may influence both processes. The present findings further converge with the recent observation that distinct emotions may be triggered by the intent to harm on the one hand, and the victim's harm on the other hand (Hechler \& Kessler, 2018). More specifically, anger at an agent who intends to harm is distinct from empathic concern for the victim (Hechler \& Kessler, 2018).

Why did emotionality fail to predict judgment of accidental transgressions in the current study? We see two potential explanations: the contact principle and the action/ omission distinction, which are critical to the judgment of moral transgressions (Cushman, 2013). First, the contact principle of moral judgment suggests that someone who inflicted harm directly (by physical force) is judged more severely than someone who harmed indirectly (Cushman, 2013; Greene et al., 2009). In short, not only the presence of harm induces an emotional response, but also how it has been done (i.e., giving someone poisonous food versus beating someone). The fact that harm is not inflicted directly in all our scenarios may explain why individual differences in emotionality don't explain the judgment severity of accidental harm. Second, when (accidental) harm results from an action, the transgression is judged more severely than when (accidental) harm results from an omission, an effect known as the "omission bias" (Baron \& Ritov, 2004; Spranca et al., 1991). In our study, the victim's harm resulted mostly from omissions. As a consequence, emotionality may have contributed less to the moral condemnation of harmful omissions than it would have for harmful actions.

\subsection{Conscientiousness increases judgment of moral wrongness following intentional harm}

People high in conscientiousness favor deliberative thinking more than others when making a decision (Ashton \& Lee, 2009), and we expected this to also be the case for moral judgment. More specifically, we reasoned that the careful examination of intentionality may play a greater role in people with high conscientiousness. Accordingly, we expected a contribution of conscientiousness to the judgment of accidental harm especially, because this is a situation in which the output of the intent-based and outcome-based processes are opposed and whereby deliberation is presumably needed to solve the 
conflict (Greene, 2007; Greene et al., 2004). However, conscientiousness did not influence judgment of accidents in the present study. Rather, we found that conscientiousness was associated with less acceptability of the agent's behavior following intentional transgressions.

Previous studies on moral dilemmas have found that greater deliberation was associated with greater acceptability of inflicting harm for utilitarian motives (Bartels, 2008; Behnke et al., 2020), and accepting harm as a mean to preserve the greater good was cognitively demanding (Greene et al., 2008; Suter \& Hertwig, 2011; Trémolière et al., 2012). The present study complements this literature by suggesting that deliberative thinking may additionally modulate moral outrage following unfair or evitable harm, that is, when an agent harmed intentionally without utilitarian motives.

\subsection{Honesty-Humility modulates moral outrage, but not punishment decisions}

We expected honesty-humility to be more sensitive to the intent to harm, and thus to be associated with more severe judgment of intentional and attempted transgressions. On the contrary, honesty-humility was negatively correlated with acceptability of the agent's behavior following accidental transgressions.

This finding seems hardly reconcilable with previous evidence indicating that people are particularly sensitive to the unfairness component of harmful events. Moral outrage following harm is, for instance, higher if harm serves unfair motives (Fehr \& Gächter, 2002), and prosocial attitude is associated with a greater need for justice in third parties in order to compensate for unfair harm (Pfattheicher et al., 2019). Honesty-humility also predicts desirability of revenge (Edwin Sheppard \& Boon, 2012). Despite this indirect evidence that honesty-humility may be associated with harsher judgment of intentional and attempted transgressions, individual variability in this trait failed to predict outrage and condemnation of a malevolent agent in the current study.

By contrast, this finding may support the idea that honesty-humility is related to aversion to actual harmful outcomes rather than aversion to harmful intents. Such aversion may thus predict greater 
moral outrage when an agent accidentally harms another. In people with dark personalities, who are less reluctant to inflict harm, honesty-humility indeed seems to reduce utilitarianism (Djeriouat \& Trémolière, 2014). However, since honesty-humility also reduced acceptability in the neutral condition, this result should be interpreted with caution.

Interestingly, honesty-humility modulated judgments of acceptability, but not judgments of punishment and blame. This suggests that individual variability in this trait is more predictive of moral outrage than it is of punishment. Even though punishment decisions and moral outrage at third parties are correlated overall (Hechler \& Kessler, 2018), individuals with high honesty-humility may not necessarily punish an agent in proportion to the harm done or to the outrage triggered. Speculatively, because honesty-humility is associated with cooperation (Hilbig et al., 2013), concern for justice in individuals scoring high on this trait may be more oriented toward compensation for the victim and rehabilitation of the agent, and less so toward retributive punishment.

\section{Conclusion}

In sum, we found that personality plays a moderate, yet selective role in third-party moral judgment. Our study suggests that some personality traits may contribute both to the intent-based and outcome-based processes of moral judgment, while others may modulate one of these two processes. With this respect, it calls for further investigation of the sub-processes underlying the examination of intent and outcome. Future work should study the interaction between individual dispositions and contextual factors in thirdparty moral judgment. An interesting avenue is for instance how identification with the agent or the victim modulates judgment of different types of transgressions. 


\section{Conflict of interest}

The authors declare no conflict of interest

\section{Informed consent.}

Participants completed the experiment only if they wished to do so.

All procedures performed in this study were in accordance with the 1964 Helsinki declaration and its later amendments.

\section{Author contribution}

Flora Schwartz : Investigation ; Data curation; Visualization ; Formal analysis ; Writing - original draft ; Writing - review and editing

Hakim Djeriouat : Funding acquisition ; Conceptualization ; Writing - review and editing

Bastien Trémolière : Funding acquisition ; Conceptualization ; Methodology ; Project administration ; Writing - review and editing

\section{Acknowledgments}

This work was supported by an ANR grant (ANR-19-CE28-0002).

\section{Data availability statement}

The data, scripts and pre-registration report will be made publicly available pending publication at the following webpage: https://osf.io/n6ht3 (they are currently under embargo). 


\section{References}

Ashton, M., \& Lee, K. (2009). The HEXACO-60: A Short Measure of the Major Dimensions of Personality. Journal of Personality Assessment, 91(4), 340-345. https://doi.org/10.1080/00223890902935878

Babalola, M. T., Bligh, M. C., Ogunfowora, B., Guo, L., \& Garba, O. A. (2019). The Mind is Willing, but the Situation Constrains: Why and When Leader Conscientiousness Relates to Ethical Leadership. Journal of Business Ethics, 155(1), 75-89. https://doi.org/10.1007/s10551-017$3524-4$

Baron, J., \& Ritov, I. (2004). Omission bias, individual differences, and normality. Organizational Behavior and Human Decision Processes, 94(2), 74-85.

https://doi.org/10.1016/j.obhdp.2004.03.003

Bartels, D. M. (2008). Principled moral sentiment and the flexibility of moral judgment and decision making. Cognition, 108(2), 381-417. https://doi.org/10.1016/j.cognition.2008.03.001

Behnke, A., Strobel, A., \& Armbruster, D. (2020). When the killing has been done: Exploring associations of personality with third-party judgment and punishment of homicides in moral dilemma scenarios. PLOS ONE, 15(6), e0235253. https://doi.org/10.1371/journal.pone.0235253

Bird, G., \& Cook, R. (2013). Mixed emotions: The contribution of alexithymia to the emotional symptoms of autism. Translational Psychiatry, 3, e285. PubMed. https://doi.org/10.1038/tp.2013.61

Brady, J. P. (1983). Fair and impartial railroad: The jury, the media, and political trials. Journal of Criminal Justice, 11(3), 241-263. https://doi.org/10.1016/0047-2352(83)90117-4

Clark, J. W., \& Wink, K. (2012). The relationship between political ideology and punishment: What do jury panel members say? Applied Psychology in Criminal Justice, 8(2), 130-146.

Conway, P., Goldstein-Greenwood, J., Polacek, D., \& Greene, J. D. (2018). Sacrificial utilitarian judgments do reflect concern for the greater good: Clarification via process dissociation and the judgments of philosophers. Cognition, 179, 241-265.

https://doi.org/10.1016/j.cognition.2018.04.018

Crockett, M. J., Clark, L., Hauser, M. D., \& Robbins, T. W. (2010). Serotonin selectively influences moral judgment and behavior through effects on harm aversion. Proceedings of the National Academy of Sciences, 107(40), 17433-17438. https://doi.org/10.1073/pnas.1009396107 
Cushman, F. (2008). Crime and punishment: Distinguishing the roles of causal and intentional analyses in moral judgment. Cognition, 108(2), 353-380. https://doi.org/10.1016/j.cognition.2008.03.006

Cushman, F. (2013). Action, Outcome, and Value: A Dual-System Framework for Morality. Personality and Social Psychology Review, 17(3), 273-292. https://doi.org/10.1177/1088868313495594

Cushman, F., \& Young, L. (2009). The Psychology of Dilemmas and the Philosophy of Morality. Ethical Theory and Moral Practice, 12(1), 9-24. https://doi.org/10.1007/s10677-008-9145-3

Devine, D. J., Clayton, L. D., Dunford, B. B., Seying, R., \& Pryce, J. (2001). Jury decision making: 45 years of empirical research on deliberating groups. Psychology, Public Policy, and Law, 7(3), 622-727. https://doi.org/10.1037/1076-8971.7.3.622

Djeriouat, H., \& Trémolière, B. (2014). The Dark Triad of personality and utilitarian moral judgment: The mediating role of Honesty/Humility and Harm/Care. Personality and Individual Differences, 67, 11-16. https://doi.org/10.1016/j.paid.2013.12.026

Edwin Sheppard, K., \& Boon, S. D. (2012). Predicting appraisals of romantic revenge: The roles of Honesty-Humility, Agreeableness, and vengefulness. Personality and Individual Differences, 52(2), 128-132. https://doi.org/10.1016/j.paid.2011.09.014

Exline, J. J., \& Geyer, A. L. (2004). Perceptions of Humility: A Preliminary Study. Self and Identity, 3(2), 95-114. https://doi.org/10.1080/13576500342000077

Fehr, E., \& Gächter, S. (2002). Altruistic punishment in humans. Nature, 415(6868), 137-140. https://doi.org/10.1038/415137a

Feinberg, M., Willer, R., Antonenko, O., \& John, O. (2012). Liberating Reason From the Passions: Overriding Intuitionist Moral Judgments Through Emotion Reappraisal. Psychological Science, 23, 788-795. https://doi.org/10.1177/0956797611434747

Fleming, K. A., Heintzelman, S. J., \& Bartholow, B. D. (2016). Specifying Associations Between Conscientiousness and Executive Functioning: Mental Set Shifting, Not Prepotent Response Inhibition or Working Memory Updating: Specifying Associations Between Conscientiousness and Executive Functioning. Journal of Personality, 84(3), 348-360. https://doi.org/10.1111/jopy.12163

Furnham, A., Richards, S. C., \& Paulhus, D. L. (2013). The Dark Triad of Personality: A 10 Year Review: Dark Triad of Personality. Social and Personality Psychology Compass, 7(3), 199-216. https://doi.org/10.1111/spc3.12018 
Green, M., Piel, J. A., \& Flowers, C. (2008). Reversing Education Majors' Arithmetic Misconceptions With Short-Term Instruction Using Manipulatives. The Journal of Educational Research, 101(4), 234-242. https://doi.org/10.3200/JOER.101.4.234-242

Greene, J. D. (2007). Why are VMPFC patients more utilitarian? A dual-process theory of moral judgment explains. Trends in Cognitive Sciences, 11(8), 322-323. https://doi.org/10.1016/j.tics.2007.06.004

Greene, J. D., Cushman, F., Stewart, L., Lowenberg, K., Nystrom, L. E., \& Cohen, J. D. (2009). Pushing moral buttons: The interaction between personal force and intention in moral judgment. Cognition, 111(3), 364-371.

Greene, J. D., Morelli, S. A., Lowenberg, K., Nystrom, L. E., \& Cohen, J. D. (2008). Cognitive load selectively interferes with utilitarian moral judgment. Cognition, 107(3), 1144-1154. https://doi.org/10.1016/j.cognition.2007.11.004

Greene, J. D., Nystrom, L. E., Engell, A. D., Darley, J. M., \& Cohen, J. D. (2004). The Neural Bases of Cognitive Conflict and Control in Moral Judgment. Neuron, 44(2), 389-400. https://doi.org/10.1016/j.neuron.2004.09.027

Greene, J. D., Sommerville, R. B., Nystrom, L. E., Darley, J. M., \& Cohen, J. D. (2001). An fMRI Investigation of Emotional Engagement in Moral Judgment. Science, 293(5537), 2105. https://doi.org/10.1126/science.1062872

Gunnell, J. J., \& Ceci, S. J. (2010). When emotionality trumps reason: A study of individual processing style and juror bias. Behavioral Sciences \& the Law, 28(6), 850-877. https://doi.org/10.1002/bsl.939

Hart, W., Kinrade, C., Tortoriello, G. K., Richardson, K., \& Breeden, C. J. (2020). Identifying with the "bad" guy: A novel account for apparent moral-judgment deficiencies in antagonistic personality. Personality and Individual Differences, 166, 110161. https://doi.org/10.1016/j.paid.2020.110161

Hechler, S., \& Kessler, T. (2018). On the difference between moral outrage and empathic anger: Anger about wrongful deeds or harmful consequences. Journal of Experimental Social Psychology, 76, 270-282. https://doi.org/10.1016/j.jesp.2018.03.005

Hilbig, B. E., Zettler, I., Leist, F., \& Heydasch, T. (2013). It takes two: Honesty-Humility and Agreeableness differentially predict active versus reactive cooperation. Personality and Individual Differences, 54(5), 598-603. https://doi.org/10.1016/j.paid.2012.11.008 
Kang, J., Bennett, M., Carbado, D., \& Casey, P. (2012). Implicit bias in the courtroom. UCLA Law Review, 59(5), 1124-1187.

Kaplan, M. F., \& Miller, L. E. (1978). Reducing the effects of juror bias. Journal of Personality and Social Psychology, 36(12), 1443-1455. https://doi.org/10.1037/0022-3514.36.12.1443

Karandikar, S., Kapoor, H., Fernandes, S., \& Jonason, P. K. (2019). Predicting moral decision-making with dark personalities and moral values. Personality and Individual Differences, 140, 70-75. https://doi.org/10.1016/j.paid.2018.03.048

Kuznetsova, A., Brockhoff, P. B., \& Christensen, R. H. B. (2017). ImerTest Package: Tests in Linear Mixed Effects Models. Journal of Statistical Software, 82(13). https://doi.org/10.18637/jss.v082.i13

Lane, R. D., Weihs, K. L., Herring, A., Hishaw, A., \& Smith, R. (2015). Affective agnosia: Expansion of the alexithymia construct and a new opportunity to integrate and extend Freud's legacy. Neuroscience \& Biobehavioral Reviews, 55, 594-611. https://doi.org/10.1016/j.neubiorev.2015.06.007

Lee, K., \& Ashton, M. (2008). The HEXACO personality factors in the indigenous personality lexicons of English and 11 other languages. Journal of Personality, 76(5), 1001-1054.

Lenth, R. V. (2016). Least-Squares Means: The R Package lsmeans. Journal of Statistical Software, 69(1), 1-33. https://doi.org/10.18637/jss.v069.i01

Luke, S. G. (2017). Evaluating significance in linear mixed-effects models in R. Behavior Research Methods, 49(4), 1494-1502. https://doi.org/10.3758/s13428-016-0809-y

Moll, J., \& de Oliveira-Souza, R. (2007). Moral judgments, emotions and the utilitarian brain. Trends in Cognitive Sciences, 11(8), 319-321. https://doi.org/10.1016/j.tics.2007.06.001

Moll, J., de Oliveira-Souza, R., \& Eslinger, P. J. (2003). Morals and the human brain: A working model. Neuroreport, 14(3), 299-305. https://doi.org/10.1097/00001756-200303030-00001

Moran, J. M., Young, L. L., Saxe, R., Lee, S. M., O’Young, D., Mavros, P. L., \& Gabrieli, J. D. (2011). Impaired theory of mind for moral judgment in high-functioning autism. Proceedings of the National Academy of Sciences, 108(7), 2688. https://doi.org/10.1073/pnas.1011734108

Nichols, S., \& Mallon, R. (2006). Moral dilemmas and moral rules. Cognition, 100(3), 530-542. https://doi.org/10.1016/j.cognition.2005.07.005

Patil, I., \& Silani, G. (2014a). Reduced empathic concern leads to utilitarian moral judgments in trait alexithymia. Frontiers in Psychology, 5. https://doi.org/10.3389/fpsyg.2014.00501 
Patil, I., \& Silani, G. (2014b). Alexithymia increases moral acceptability of accidental harms. Journal of Cognitive Psychology, 26(5), 597-614. https://doi.org/10.1080/20445911.2014.929137

Patil, I., Zucchelli, M. M., Kool, W., Campbell, S., Fornasier, F., Calò, M., Silani, G., Cikara, M., \& Cushman, F. (2021). Reasoning supports utilitarian resolutions to moral dilemmas across diverse measures. Journal of Personality and Social Psychology, 120(2), 443-460. https://doi.org/10.1037/pspp0000281

Paulhus, D. L., \& Williams, K. M. (2002). The Dark Triad of personality: Narcissism, Machiavellianism, and psychopathy. Journal of Research in Personality, 36(6), 556-563. https://doi.org/10.1016/S0092-6566(02)00505-6

Pennington, N., \& Hastie, R. (1986). Evidence evaluation in complex decision making. Journal of Personality and Social Psychology, 51(2), 242-258. https://doi.org/10.1037/0022-3514.51.2.242

Perugini, M., Gallucci, M., Presaghi, F., \& Ercolani, A. P. (2003). The personal norm of reciprocity. European Journal of Personality, 17(4), 251-283. https://doi.org/10.1002/per.474

Pfattheicher, S., Sassenrath, C., \& Keller, J. (2019). Compassion magnifies third-party punishment. Journal of Personality and Social Psychology, 117(1), 124-141. https://doi.org/10.1037/pspi0000165

Reynolds, S. J. (2008). Moral attentiveness: Who pays attention to the moral aspects of life? Journal of Applied Psychology, 93(5), 1027-1041. https://doi.org/10.1037/0021-9010.93.5.1027

Roberts, B. W., Lejuez, C., Krueger, R. F., Richards, J. M., \& Hill, P. L. (2014). What is conscientiousness and how can it be assessed? Developmental Psychology, 50(5), 1315-1330. https://doi.org/10.1037/a0031109

Schriber, R. A., Robins, R. W., \& Solomon, M. (2014). Personality and self-insight in individuals with autism spectrum disorder. Journal of Personality and Social Psychology, 106(1), 112-130. PubMed. https://doi.org/10.1037/a0034950

Shaffer, D. R., \& Case, T. (1982). On the decision to testify in one's own behalf: Effects of withheld evidence, defendant's sexual preferences, and juror dogmatism on juridic decisions. Journal of Personality and Social Psychology, 42(2), 335-346. https://doi.org/10.1037/0022-3514.42.2.335

Shaffer, D. R., Plummer, D., \& Hammock, G. (1986). Hath he suffered enough? Effects of jury dogmatism, defendant similarity, and defendant's pretrial suffering on juridic decisions. Journal of Personality and Social Psychology, 50(5), 1059-1067. https://doi.org/10.1037/00223514.50.5.1059 
Spranca, M., Minsk, E., \& Baron, J. (1991). Omission and commission in judgment and choice. Journal of Experimental Social Psychology, 27(1), 76-105. https://doi.org/10.1016/0022-1031(91)90011$\mathrm{T}$

Suter, R. S., \& Hertwig, R. (2011). Time and moral judgment. Cognition, 119(3), 454-458. https://doi.org/10.1016/j.cognition.2011.01.018

Tomasello, M., \& Vaish, A. (2013). Origins of human cooperation and morality. Annual Review of Psychology, 64, 231-255.

Trémolière, B., \& Djeriouat, H. (2016). The sadistic trait predicts minimization of intention and causal responsibility in moral judgment. Cognition, 146, 158-171. https://doi.org/10.1016/j.cognition.2015.09.014

Trémolière, B., Neys, W. D., \& Bonnefon, J.-F. (2012). Mortality salience and morality: Thinking about death makes people less utilitarian. Cognition, 124(3), 379-384. https://doi.org/10.1016/j.cognition.2012.05.011

van Doorn, J., Zeelenberg, M., Breugelmans, S. M., Berger, S., \& Okimoto, T. G. (2018). Prosocial consequences of third-party anger. Theory and Decision, 84(4), 585-599. https://doi.org/10.1007/s11238-017-9652-6

Young, L., Camprodon, J. A., Hauser, M., Pascual-Leone, A., \& Saxe, R. (2010). Disruption of the right temporoparietal junction with transcranial magnetic stimulation reduces the role of beliefs in moral judgments. Proceedings of the National Academy of Sciences, 107(15), 6753-6758. https://doi.org/10.1073/pnas.0914826107

Young, Liane, Bechara, A., Tranel, D., Damasio, H., Hauser, M., \& Damasio, A. (2010). Damage to ventromedial prefrontal cortex impairs judgment of harmful intent. Neuron, 65(6), 845-851. https://doi.org/10.1016/j.neuron.2010.03.003

Zelazo, P. D., Helwig, C. C., \& Lau, A. (1996). Intention, Act, and Outcome in Behavioral Prediction and Moral Judgment. Child Development, 67(5), 2478-2492. JSTOR. https://doi.org/10.2307/1131635

Zuckerman, M. (2007). Sensation seeking and risky behavior. (pp. xix, 309). American Psychological Association. https://doi.org/10.1037/11555-000

Zuur, A. F., Ieno, E. N., Walker, N., Saveliev, A. A., \& Smith, G. M. (2009). Mixed effects models and extensions in ecology with R. Springer New York. https://doi.org/10.1007/978-0-387-87458-6 


\section{Supplementary results}

\section{Manipulation check}

To better illustrate moral judgment differences as a function of the intent by outcome combination (Supplementary Figure 1), we report the mean ratings and 95\% confidence intervals for each type of transgression as well as the relevant post-hoc pairwise comparisons computed with the lsmeans tukey tests in $\mathrm{R}$ (please note that the t-statistics reported for post-hoc analyses of mixed models (t-ratio) is not equivalent to the traditional t-statistics).

Participants rated the agent's behavior as less acceptable following intentional harm $(\mathrm{M}=0.396$, $\left.\mathrm{CI}_{95 \%}=[0.082-0.71]\right)$, as compared to attempted harm $\left(\mathrm{M}=1.45, \mathrm{CI}_{95 \%}=[1.13-1.76]\right)(b=1.05, t=$ $12.75, p<0.0001)$, the latter being judged less acceptable than accidental harm $\left(\mathrm{M}=2.91, \mathrm{CI}_{95 \%}=[2.60\right.$ 3.23]) ( $b=1.47, t=17.78, p<0.0001)$. Accidental harm was rated as less acceptable than the neutral condition $\left(\mathrm{M}=4.93, \mathrm{CI}_{95 \%}=[4.61-5.24]\right)(b=2.01, t=24.47, p<0.0001)$.

Punishment decisions were more severe for intentional harm $\left(\mathrm{M}=4.66, \mathrm{CI}_{95 \%}=[4.17-5.15]\right)$ than attempted harm $\left(\mathrm{M}=2.51, \mathrm{CI}_{95 \%}=[2.02-3.00]\right)(b=-2.16, t=25.98, p<0.0001)$, more severe for attempted than for accidental harm $\left(\mathrm{M}=2.05, \mathrm{CI}_{95 \%}=[1.56-2.54]\right)(b=-0.46, t=5.55, p<0.0001)$, and more severe for accidental harm than for the neutral condition $\left(\mathrm{M}=0.38, \mathrm{CI}_{95 \%}=[-0.11-0.87]\right)(b=-1.67$, $t=20.16, p<0.0001)$.

Finally, participants judged the agent's behavior as blameworthy more so for intentional harm (M $\left.=4.96, \mathrm{CI}_{95 \%}=[4.45-5.47]\right)$ than for attempted harm $\left(\mathrm{M}=2.85, \mathrm{CI}_{95 \%}=[2.34-3.36]\right)(b=-2.12, t=24.28$, $p<0.0001)$, which was rated more blameworthy relative to accidental harm $\left(\mathrm{M}=2.42, \mathrm{CI}_{95 \%}=[1.91\right.$ 2.93]) ( $b=-0.43, t=4.88, p<0.0001)$, and accidental harm was regarded as more blameworthy than the neutral condition $\left(\mathrm{M}=0.54, \mathrm{CI}_{95 \%}=[0.029-1.05]\right)(b=-1.89, t=21.69, p<0.0001)$.

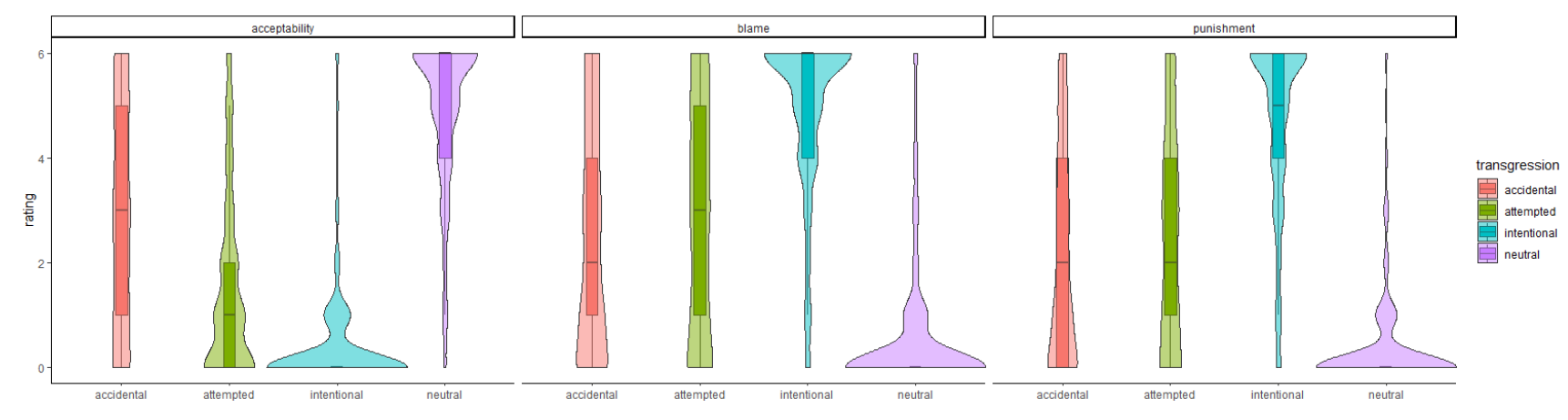

Supplementary Figure 1. Moral judgments of acceptability, punishment and blame for the different types of transgressions 
2. Gender differences in the contribution of personality traits to moral judgment

In unplanned additional analyses, we investigated whether gender influenced the contribution of honestyhumility, emotionality, and conscientiousness to moral judgments of acceptability, blame and punishment. We excluded 3 subjects who identified as "gender-neutral" or "non-binary". The main effect of gender was not significant for any moral evaluation. However, for judgments of acceptability, the main effect of conscientiousness was significant $(F=4.75, p=0.030)$ and gender interacted with conscientiousness $(F=4.34, p=0.038)$. Further investigation of this interaction revealed that conscientiousness significantly decreased acceptability of intentional harm in men $(b=-0.31, S E=0.15, t$ $=-2.10, p=0.038)$ but did not significantly influence acceptability ratings in women $(b=-0.085, S E=$ $0.083, t=-1.03, p=0.31)$. 


\section{Appendix A. List of items used in the moral judgment task.}

\section{Pool}

Matilda is walking by a neighbour's swimming pool when she sees a child about to dive in.

The child is about to dive into the deep end and have fun swimming around and playing all day.

The child is about to dive into the shallow end and smack his head very hard on the concrete bottom of the pool.

Because of a label on the side of the pool, Matilda believes that the child is about to dive safely into the deep end and swim around.

Because of a warning sign at the side of the pool, Matilda believes that the child is about to dive into shallow water and break his neck.

Matilda walks by, without saying anything to the child. The child dives in and is fine.

Matilda walks by, without saying anything to the child. The child dives in and breaks his neck.

\section{Mushrooms}

Carlotta and an acquaintance are camping in the woods. Carlotta spots some wild mushrooms growing along the campsite. Carlotta studies the mushrooms and consults her plant life guide.

The mushrooms happen to be edible and delicious. They are the kind that one can buy in the supermarket and put in salad.

The mushrooms happen to be lethal and tasteless. They are the kind that result in painful convulsions and ultimately death.

Carlotta sees a picture of an edible mushroom in her book that looks just like these mushrooms at the campsite, so she believes that the mushrooms are edible.

Carlotta sees a picture of a lethal mushroom in her book that looks just like these mushrooms at the campsite, so she believes that the mushrooms are lethal.

Carlotta offers the mushrooms to her acquaintance. Her acquaintance eats them and finds them very tasty. 
Carlotta offers the mushrooms to her acquaintance. Her acquaintance eats them and starts convulsing after 10 minutes.

\section{Seatbelt/Amusement Park}

Giovanni works at an old and very small amusement park. His job is to operate one of the rides. One of the customers finds the seatbelts uncomfortable, so he leaves them unfastened.

The ride is actually quite tame, so wearing seatbelts is really unnecessary. Nobody has ever been injured before riding without seatbelts.

The ride is actually quite bumpy and dangerous, so anyone not wearing a seatbelt risks getting tossed and getting hurt.

Having heard from his friend who operated this ride before, Giovanni thinks that the seatbelts aren't necessary at all for this ride.

Having heard from his friend who operated this ride before, Giovanni thinks that the seatbelts are totally necessary for this ride.

Giovanni keeps his mouth shut as the customer sits without fastening his seatbelt. The customer enjoys the ride just like everyone else.

Giovanni keeps his mouth shut as the customer sits without fastening his seatbelt. The customer gets tossed during the ride and suffers a severe concussion.

\section{Veterinarian/Dog poison}

Roberto is a student working at a veterinarian's office. His friend comes to visit him and sees cookies shaped like bones laying out in the worker's lounge. His friend asks if he can eat one.

One of Roberto's coworkers had baked the cookies for her birthday and had put them out for others to enjoy. They are delicious and safe to eat.

One of Roberto's co-workers had put the cookies in the lounge by accident. They are used to put dogs to sleep, so they are poisonous to eat.

Roberto believes that the cookies are safe to eat, since they are out in the workers' lounge where people normally put food to share. 
Roberto believes that the cookies are poisonous, because they are the shape of the cookies the veterinarian uses with special chemicals to put dogs to sleep.

Roberto invites his friend to eat a dog bone-shaped cookie. His friend enjoys the cookie and asks for a second one.

Roberto invites his friend to eat a dog bone-shaped cookie. His friend breaks into a sweat after several bites, stops breathing, and needs to be hospitalized.

\section{Laptop}

Claudio is a new computer technician at a store. A customer comes to the store to get her laptop checked out. The laptop gets very hot after only 10 min of work.

The laptop is within the normal range in terms of heating up with use. It is totally safe to use on one's desk and lap.

The laptop is malfunctioning and heats up much more than normal. It is dangerous to use, especially on one's lap.

Claudio checks with his boss and comes back believing it is very normal for all laptops to heat up during use.

Claudio checks with his boss and comes back believing that many laptops will catch on fire if they overheat and cause burns.

Claudio returns the laptop to the customer. The customer goes home, and uses her laptop to get a lot of important work done.

Claudio returns the laptop to the customer. The customer goes home, and her laptop catches on fire. She suffers painful second-degree burns.

\section{Motorboat}

Alessandro is driving his motorboat in the bay, on his way home. He spots a swimmer in the far distance.

The swimmer is in fact fine and is waving at Alessandro for fun as he does with people in the bay. The swimmer is in fact drowning and is waving frantically at Alessandro for help. 
Alessandro sees the swimmer waving and believes that the swimmer is waving an enthusiastic "hello".

Alessandro sees the swimmer waving and believes that the swimmer is drowning and waving desperately for help because his arm motions are so emphatic.

Alessandro drives home, leaving the swimmer behind. The swimmer is fine.

Alessandro drives home, leaving the swimmer behind. The swimmer drowns.

\section{Chairlift}

Sara is on winter break. She is running a chair lift at a ski lodge. She has just taken over after lunch break and is starting her afternoon shift. The first passenger is a child.

This afternoon, the chair lift is functioning perfectly normally and can safely carry passengers of any size up the side of the ski slope.

This afternoon, a problem with the electricity is making the old chairs bounce violently, making the lift dangerous for small passengers.

Sara believes that the ski lift is in good condition and is safe for anyone to ride, as usual. She saw her coworker had sent a group of children on the chairlift before lunch.

Sara believes that the ski lift is in bad condition and is unsafe for children in particular since her supervisor told her that it was malfunctioning before lunch.

Sara starts the chairlift, and the child gets on. The child has a safe ride to the top of the ski slope, skis down the hill, and returns to the chairlift again and again.

Sara starts the chairlift, and the child gets on. About half way through the ride the chairlift makes a massive jolt, dislodging the child who falls in the snow few feet down and sustains severe injuries.

\section{Asthma}

Erica is driving home when she sees a runner by the side of the road. The runner is bent over and has one hand on his chest. There is an empty asthma inhaler on the ground.

The runner is just short of breath and has stopped to rest for a moment before continuing his long jog. 
The runner is having a serious asthma attack and needs to get to a hospital immediately before he goes into shock.

Because Erica doesn't see the inhaler, she believes that the runner has just stopped to catch his breath and will continue his jog shortly.

Because Erica sees the inhaler and the gasping runner, she believes that the runner is having an asthma attack and must get to a hospital immediately.

Erica continues to drive, leaving the runner. The runner catches his breath and is fine.

Erica continues to drive, leaving the runner. The runner faints and collapses. 


\section{Appendix B. Correlation coefficients (and p values) between the personality traits scores and moral}

judgments.

\begin{tabular}{|c|c|c|c|c|c|c|c|}
\hline & 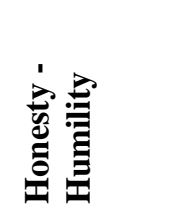 & 牚 & 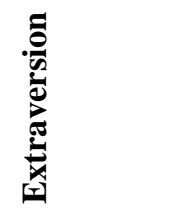 & 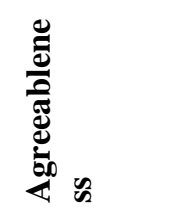 & 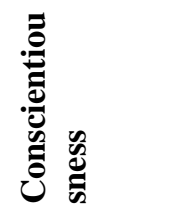 & 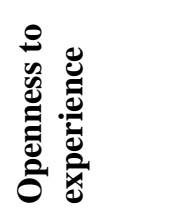 & 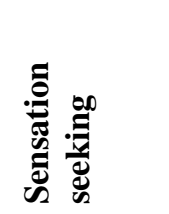 \\
\hline \multicolumn{8}{|l|}{ Acceptability } \\
\hline Accidental & $-0.11(0.0042)$ & $0.011(0.78)$ & $-0.049(0.19)$ & $-0.016(0.68)$ & $-0.031(0.41)$ & $0.043(0.25)$ & $0.011(0.78)$ \\
\hline Attempted & $-0.084(0.025)$ & $0.070(0.067)$ & $-0.031(0.42)$ & $\begin{array}{l}-0.0082 \\
(0.83)\end{array}$ & $-0.023(0.54)$ & $\begin{array}{l}-0.083 \\
(0.028)\end{array}$ & $\begin{array}{l}-0.0017 \\
(0.96)\end{array}$ \\
\hline Intentional & $-0.021(0.57)$ & $-0.072(0.058)$ & $-0.018(0.63)$ & $0.0094(0.80)$ & $-0.10(0.0086)$ & $0.027(0.47)$ & $0.037(0.33)$ \\
\hline Neutral & $-0.11(0.0036)$ & $-0.035(0.36)$ & $-0.017(0.64)$ & $-0.053(0.16)$ & $-0.0069(0.86)$ & $0.0028(0.94)$ & $-0.027(0.48)$ \\
\hline \multicolumn{8}{|l|}{ Punishment } \\
\hline Accidental & $0.024(0.53)$ & $-0.048(0.21)$ & $-0.046(0.22)$ & $-0.014(0.71)$ & $0.019(0.62)$ & $-0.028(0.45)$ & $0.060(0.11)$ \\
\hline Attempted & $0.048(0.21)$ & $0.057(0.13)$ & $0.038(0.32)$ & $0.077(0.044)$ & $-0.011(0.77)$ & $-0.022(0.56)$ & $0.068(0.86)$ \\
\hline Intentional & $0.030(0.43)$ & $0.040(0.30)$ & $0.052(0.17)$ & $-0.037(0.33)$ & $0.041(0.28)$ & $-0.036(0.34)$ & $0.015(0.69)$ \\
\hline Neutral & $-0.0073(0.85)$ & $0.049(0.20)$ & $0.026(0.50)$ & $0.019(0.61)$ & $0.0033(0.93)$ & $0.040(0.28)$ & $0.0093(0.80)$ \\
\hline \multicolumn{8}{|l|}{ Blame } \\
\hline Accidental & $0.018(0.63)$ & $-0.064(0.091)$ & $0.085(0.024)$ & $-0.040(0.29)$ & $0.012(0.75)$ & $-0.012(0.76)$ & $0.064(0.090)$ \\
\hline Attempted & $0.080(0.035)$ & $0.070(0.067)$ & $0.050(0.19)$ & $0.074(0.051)$ & $0.028(0.46)$ & $-0.006(0.88)$ & $-0.054(0.15)$ \\
\hline Intentional & $0.019(0.62)$ & $0.047(0.22)$ & $0.042(0.27)$ & $-0.062(0.10)$ & $0.020(0.60)$ & $-0.028(0.46)$ & $0.015(0.70)$ \\
\hline Neutral & $-0.0020(0.96)$ & $0.074(0.050)$ & $0.038(0.32)$ & $0.020(0.61)$ & $-0.017(0.65)$ & $0.033(0.38)$ & $0.023(0.54)$ \\
\hline
\end{tabular}

Note: no correlation survived a stringent, conservative threshold after correcting for multiple comparisons, $\alpha / 28)$. 